\title{
Language Disorder
}

National Cancer Institute

\section{Source}

National Cancer Institute. Language Disorder. NCI Thesaurus. Code C97155.

A category of disorders characterized by an impairment in the development of an individual's language capabilities, which is in contrast to his/her non-verbal intellect. 